\title{
Outline of the Activity of the Japanese MAGSAT Team
}

\author{
Naoshi FukUSHIMA \\ Chairman, Japanese MAGSAT Team, \\ Geophysics Research Laboratory, University of Tokyo, Tokyo, Japan \\ Formation of the MAGSAT Team in Japan
}

In September 1978, NASA issued the Announcement of Opportunity for participation in the analysis of MAGSAT data. Letters of intent were sent to NASA from both H. MAEDA and N. FunuShima in November 1978. The announcement from NASA was a trigger for the community of geomagnetists in Japan to consider the most effective way they might be able to utilize the valuable MAGSAT data.

In order to discuss this subject, an informal meeting was convened in Tokyo on December 21, 1978, involving geomagnetists from four universities and five governmental institutions. This meeting resolved the formation of a national investigation team for MAGSAT data analysis, which team was charged to write an official proposal to NASA. Based on the discussion at this meeting, the MAGSAT team was formed in Japan in January 1979.

\section{Membership of the Japanese MAGSAT Team}

The initial membership of the MAGSAT Team was as follows:

Chairman: N. FUKUSHIMA (Geophysics Research Laboratory, University of Tokyo)

Vice-Chairman: H. MAEDA (Geophysical Institute, Kyoto University)

Secretary: T. YUKUTAKE (Earthquake Research Institute, University of Tokyo)

Members: $\quad$ T. ARAKI (Data Analysis Center for Geomagnetism and Space Magnetism, Kyoto University), R. FuJII (National Institute of Polar Research), H. FUKUNISHI (National Institute of Polar Research), T. IIJIMA (Geophysics Research Laboratory, University of Tokyo), Y. KAMIDE (Department of Computer Science, Kyoto Sangyo University), K. Kaminuma (National Institute of Polar Research), $\mathbf{M}$. KAWAMURA (Kakioka Magnetic Observatory), $\mathrm{K}$. KoBAYASHI (Ocean Research Institute, University of Tokyo), M. Kono (Department of Applied Physics, Tokyo Institute of Technology), H. Mizuno (Geographical Survey Institute), K. OGAWA (Geological Survey of Japan), S. Oshima (Hydrographic Department, Maritime Safety 
Agnecy), T. SAITo (Geophysical Institute, Tohoku University), N. Sumitomo (Department of Geoscience, College of Liberal Arts, Kyoto University), A. SuzUKI (Geophysical Institute, Kyoto University; later moved to College of Liberal Arts, Saga University), M. TANAKA (Geographical Survey Institute), and S. UYEDA (Earthquake Research Institute, University of Tokyo).

There was of course a slight modification of team members during the analysis period of 1979-1983. H. MizUnO was replaced by Y. MiYAZAKI in the same institute. T. IIJIMA was appointed executive secretary beginning in April 1981. The following collaborators joined the MAGSAT Team for actual analysis of MAGSAT data during the investigation period:

I. NAKAgAwA (Earthquake Research Institute, University of Tokyo),

T. NAKATSUKA and Y. ONO (Geological Survey of Japan),

M. Yanagisawa (Institute of Space and Astronautical Science),

T. Kamei, T. Iyemori, S. Tsunomura, and T. Kumaki (Geophysical Institute, Kyoto University),

M. EJIRI and H. SAKURAI (National Institute of Polar Research).

The follwing persons participated in the analysis of ground or airborne magnetic survey data, the results of which will be fully used in the near future for comparison with MAGSAT data:

Y. Ueda, K. Onodera, T. Kaneko, and H. Nakagawa (Hydrographic Department, Maritime Safety Agency),

S. FuJiTA (Kakioka Magnetic Observatory),

K. Shibuya (National Institute of Polar Research).

Proposal from the Japanese Team

An official proposal was sent to NASA in February 1979, which described the objectives and the methods of approach for the MAGSAT data analysis. This proposal was tentatively accepted by NASA in July 1979. The Japanese team was asked later to send some supplementary information, before the proposal was finally adopted in the official document agreed on 21 April 1980 between NASA and the Japanese government (represented by the International Science Division, Science and International Affairs Bureau, Ministry of Education, Science and Culture).

The proposal from Japan was code-named M-43 by NASA, with the content shown below.

Statement of Work M-43

1. Objectives

A. Crustal structure near Japan and its Antarctic station 
Study the crustal structure near Japan and its Antarctic base by constructing a model of the regional magnetic field and investigating the local magnetic anomalies and their origin.

B. Electric currents and hydromagnetic waves in the ionosphere and the magnetosphere

Investigate ionospheric and magnetospheric contributions to geomagnetic variations, field-aligned currents, geomagnetic pulsations and hydromagnetic waves by comparison of MAGSAT data with ground magnetic observations.

\section{Approach}

A.1. Regional magnetic charts

A model of the regional geomagnetic field over the Japanese islands and neighborhood for the epoch 1980.0 will be constructed. This model will be expressed in a polynomial series with longitude and latitude, although analytical expressions other than the polynomial series will also be investigated. Surface data will be combined with the Magsat data to make the model. Regional charts of the geomagnetic components will then be drawn on the basis of the derived model.

\section{A.2. Local magnetic anomalies and their origin}

Local magnetic anomalies will be extended and their origin investigated. There are two ways to extract the local magnetic anomalies. One is the straightforward comparison of the observed data with the regional field model, and the other is to develop the model to a sufficiently higher degree and to synthesize the higher terms only to obtain short wavelength anomalies. Using one of these methods, magnetic anomalies will be obtained from the data reduced to the surface values and to the common epoch 1980.0.

\section{A.3. Crustal structure in the Antarctic}

Crustal structure in an area near Syowa Station (Japanese Antarctic Base at $69^{\circ} 00^{\prime} \mathrm{S}, 39^{\circ} 35^{\prime} \mathrm{E}$ ) will be investigated. Aeromagnetic surveys will be conducted in an area centering at Syowa Station. Magsat data will be analyzed along with gravity and seismic data to determine the crustal structure of the Antarctic continent.

B.1. Ionospheric and magnetospheric contributions to geomagnetic variations

The main purpose is to use Magsat data to determine the contribution to geomagnetic variations from electric currents of magnetospheric and ionospheric origins, and to study the ionospheric current in detail. Ionospheric and magnetospheric origins of the geomagnetic variations will be deduced through the comparison of the spherical harmonic analyses at the two levels, i.e., the satellite level (analysis of Magsat data) and on the ground (analysis of groundbased data). The Magsat data will be compared with the magnetic field value at satellite level calculated on the basis of the ground data. A similar analysis will be made also for the sudden commencements of magnetic storms.

\section{B.2. Field-aligned currents (FAC)}


The following details concerning the FAC linking ionospheric and magnetospheric currents will be studied: (1) FAC balance, (2) Relationship of FAC to auroral structure, dynamics, and brightness, (3) Relationship between FAC and ionospheric currents, (4) Altitude dependence of FAC.

The three-component magnetic field measurements by Magsat will be used to study the relative distribution of FAC at both high and low latitudes. The Magsat data will be compared with ground data from stations such as Alaska and Greenland to study the relationship of FAC with auroral electrojets in the ionosphere.

Aurora observed with all-sky cameras and television cameras will be used to study the FAC distribution in connection with auroral structure, brightness, and dynamics. The altitude dependence of FAC will be studied by analysis of Magsat data at varying altitudes or by comparison of TRIAD data or rocket data.

B.3. Geomagnetic pulsations and hydromagnetic waves

Comparison of the simultaneous ground and Magsat data will provide an analysis of short period hydromagnetic waves in the Earth's environment. Spectral analyses will be made of the geomagnetic fluctuations observed by Magsat. These analyses will include the use of a high-speed spectrum analyzer and a crossspectral analysis technique with a Chebyshev digital filter.

Spectrum and polarization analyses will be made of ground measurements of geomagnetic fluctuations using data from Japanese stations, including several stations in the Antarctic near the 80 degree geomagnetic parallel from $L=6-8$, and their conjugate points in Iceland, as well as data from central Canada from the Canada-Japan Cooperation.

\section{Tasks}

\section{A.1. Regional magnetic charts}

Using Magsat, survey, and observatory data, construct a model to describe the regional magnetic field in the area surrounding the Japanese islands and Japanese Antarctic base for the epoch 1980.0, and use this model to construct regional charts of the geomagnetic components. Compare the magnetic field data derived from the Magsat model to be supplied by NASA with those derived by polynomial fits in the Japanese region and investigate significant discrepancies.

\section{A.2. Local magnetic anomalies and their origin}

Generate a regional anomaly map by removing the general regional trend as defined by A.1. above from the observed data. Investigate methods of determining whether the observed anomalies are of crustal origin or not. For those anomalies of crustal origin, investigate the likely causes of these anomalies by comparing the anomaly data with other correlative data such as gravity data, bathymetric charts, seismic profiles and heat flow distribution. Model the anomalies in terms, for example, of the difference between an oceanic plate and a back-arc-basin.

\section{A.3. Crustal structure in the Antarctic}


Investigate crustal structure in an area near Syowa Station in Antarctica, using Magsat anomaly data, aeromagnetic survey data, and other appropriate ground data. Investigate the secular variation in the Antarctic region by comparing Magsat data with magnetic charts constructed in 1975 by the Geographical Survey Institute.

B.1. Ionospheric and magnetospheric contributions to geomagnetic variations

Conduct spherical harmonic analysis of geomagnetic components to separate the total magnetic potential into parts with origin internal and external to the satellite level. Separate the magnetic variations into those of ionospheric, magnetospheric, and crust/mantle origin. Investigate the magnetospheric effect of (Solar quiet) Sq current system along the dawn-dusk meridian. Study the electromagnetic structure of the Earth's interior through analysis of sudden commencements at the spacecraft and on the ground.

\section{B.2. Field-aligned currents (FAC)}

Investigate $\mathrm{FAC}$ in the magnetosphere and determine the latitudinal profile and flow directions of FAC in the dawn-dusk meridian. Study the seasonal dependence or asymmetry of FAC in the Northern and Southern Hemisphere. Examine the possible relationship between FAC and the auroral electrojet.

B.3. Geomagnetic pulsations and hydromagnetic waves

Study the occurrence, polarization, and propagation characteristics of hydromagnetic waves in the magnetosphere through techniques such as spectral analysis of Magsat data, and investigate the source of these waves.

The final report shall specifically describe, at a minimum, the results of each of the above tasks. The specific methodologies and interpretation techniques (including programs) applied to address each shall be discussed in sufficient detail so that they can be completely understood. References to other publications are acceptable if their level of detail is adequate. If references as noted above are utilized, copies or excerpts from these references shall be provided along with the final report. The final report shall identify and discuss any significant results derived as a result of the Magsat project. The report shall describe any new models constructed as a result of this project as well as describe how they were constructed, and how they differ from the existing model(s).

\section{Support for the Japanese MAGSAT Team}

When the Japanese team wrote its official proposal to NASA, Professors T. NAGATA (National Institute of Polar Research) and T. Rikitake (Tokyo Institute of Technology, later Nihon University) were asked to be advisors. From members of the National Committee for IUGG, an advisory committee was formed in September 1979, with the purpose of (1) giving appropriate scientific advice to the MAGSAT Team, and (2) promoting the future possible utilization of MAGSAT data in the various disciplines of geophysics beyond the subjects chosen by the MAGSAT Team. 
As to the financial support, the MAGSAT Team was eligible to receive a special grant-in-aid from the Ministry of Education, Science and Culture, for the period of 1980-82, which could be used mainly for (1) reproduction and editing of MAGSAT data tapes for workers at various locations in Japan, (2) the meetings of the team held every four months, and (3) preparation and printing of the Progress and Final Reports.

\section{Progress and Final Reports from the Japanese Team}

According to the agreement between NASA and the MAGSAT Investigaiton Team in Japan, the reports were submitted to NASA as follows:

Report Title

First Progress Report Second Progress Report Third Progress Report Fourth Progress Report Fifth Progress Report Sixth Progress Report Draft Final Report Final Report
Investigation Period

July 15-Nov. 15,1980 November 28,1980 Nov. 15, 1980-March 15, 1981 March 28, 1981 Mar. 15-July 15, 1981 July 20, 1981

July 15-Nov. 30, 1981 December 15, 1981 Dec. 1 1981-March 30, 1982 April 5, 1982 April 1-July 31, 1982 August 5, 1982 July 15, 1980-Nov. 15, 1982 December 15, 1982 July 15, 1980-Nov. 15, 1982 March 15, 1983

The Final Report contained 34 pages of text and 33 pages of illustrations. The Japanese version of the final report appeared as the following summary paper: "Preliminary Results of Investigations with MAGSAT Data" published in the Report of the Institute of Space and Astronautical Science, Special Issue for Space Observation No.5, pages 67-114 (March 1983).

\section{Contribution to GRL April 1982 Issue on MAGSAT Results}

The following 5 papers were published in the special issue on "MAGSAT Preliminary Results"' (Geophysical Research Letters, Vol.9, No.4, April 1982), as the contributions from the Japanese MAGSAT Investigation Team.

Yanagisawa, M., M. Kono, T. Yukutake, and N. Fukushima, Preliminary interpretation of magnetic anomalies over Japan and its surrounding area, pp. 322-324 (Paper 2L0022).

Maeda, H., T. Iyemori, and T. ARAKI, New evidence of a meridional current system in the equatorial ionosphere, pp. 337-340 (Paper 2L0121).

Araki, T., T. IYemori, S. Tsunomura, T. KAMEI, and H. MAEDA, Detection of an ionospheric current for the preliminary impulse of the geomagnetic sudden commencement, pp. 341-344 (Paper 2L0157). 
Suzuki, A. and N. Fukushima, Sunward or anti-sunward electric current in space below the MAGSAT level, pp. 345-347 (Paper 2L0116).

IIJIMA, T., N. FUKUSHIMA, and R. FujII, Transverse and parallel geomagnetic pertubations over the polar regions observed by MAGSAT, pp. 369-372 (Paper 2L0355).

Papers at the MAGSAT Symposium during the IUGG Assembly in August 1983

An interdisciplinary symposium on "Scientific Discoveries from MAGSAT Investigations" was held on August 22-23, 1983, in Hamburg, Federal Republic of Germany, during the Eighteenth General Assembly of IUGG, with IAGA as the leading association and IASPEI, IAVCEI and IAPSO as the sponsoring bodies. A total of 38 papers were presented, including the following 9 papers from the Japanese MAGSAT Team and 1 paper with a Japanese co-author.

Paper 13/2, T. Araki, T. Iyemori, S. Tsunomura, and T. Kamei, Sudden commencements observed by Magsat.

Paper 13/3, A. Suzuki, N. Fukushima, and M. Yanagisawa, Anti-sunward space current below the Magsat level during magnetic storms and its possible connection with partial ring current in the magnetosphere.

Paper 13/4, H. MAEDA, T. KAMEI, T. IYemori, and T. ARAKI, Geomagnetic perturbations at low latitudes observed by Magsat.

Paper 13/6, Y. Kamide, D. S. Evans, and J. C. CAIN, A quantitative comparison of field-aligned current signatures simultaneously observed by the Magsat and TIROS/NOAA satellites.

Paper 13/7, T. IIJIMA, N. Fukushima, and R. Fujil, Synthetic view of fieldaligned currents and ionospheric currents at high latitudes associated with strong northward interplanetary magnetic field.

Paper 13/10, T. Kamei, T. ARAKI, H. MaedA, and T. IYemori, Magnetospheric and ionospheric current systems observed at high latitude by Magsat.

Paper 13/14, M. Yanagisawa, M. Kono, N. Fukushima, and T. Yukutake, Mean ionospheric field correction of Magsat data.

Paper 13/15, M. Kono, M. Yanagisawa, N. Fukushima, and T. Yukutake, Derivation and evaluation of magnetic anomaly maps corresponding to crustal magnetization.

Paper 13/16, I. Nakagawa, T. Yukutake, and N. Fukushima, Extraction of crustal anomalies in the area of the Japanese islands.

Paper 13/17, N. Fukushima, T. Yukutake, T. NAKatsuka, I. NaKagawa, S. FujITA, and Y. UEDA, Geomagnetic anomalies over the Japanese islands and its surrounding area.

Oral Presentation by the Japanese MAGSAT Team Members

The Fourth Scientific Assembly of the International Association of Geomagnetism 
and Aeronomy, Edinburgh, Scotland, August 1981

M. Yanagisawa, M. Kono, T. Yukutake, and N. Fukushima, Magnetic anomalies over Japan and its surrounding area (submitted to the session on "Scientific Results form MAGSAT").

T. IIJIMA, N. Fukushima, and R. FujII, Characteristics of magnetic field disturbances observed by MAGSAT (submitted to the session "General Contributions to IAGA Division III").

T. IIJImA, Y. KAmide, R. FujiI, and N. Fukushima, Spatial relationship between field-aligned currents and the auroral electrojets-MAGSAT and Alaskan chain observations (submitted to the session "General Contributions to IAGA Division III'").

M. MAedA, T. KAMEI, and T. IYEMORI, Magnetic effect on Sq deduced from an analysis of MAGSAT data (submitted to the session "General Contributions to IAGA Division III", but cancelled because of the absence of the authors).

Joint Symposium on MAGSAT Results and High-Sensitive Magnetometers, September 1980 and November 1981 in Sendai

N. FukUSHIMA, International cooperative study with MAGSAT data (1980).

M. KONO and M. YANAGISAWA, Preliminary results of MAGSAT data analysis (1980).

T. NAKATSUKa, K. Ogawa, and Y. ONo, Correction for altitude change on the geomagnetic total force measurement by MAGSAT: a model study (1980).

A. SUZUKI, T. KAMEI, and T. KUMAKI, Plans for MAGSAT data analysis (1980).

H. SAKurai, M. Ejiri, R. FujiI, T. IIJima, and N. Fukushima, Reduction of MAGSAT data and some preliminary results (1980).

T. NAKATSUKA and Y. ONO, Magnetic anomaly mapping with MAGSAT data (1981).

T. YukUtake and I. NAKagawa, Analysis of magnetic anomaly by double Fourier series (1981).

I. Nakagawa and T. Yukutake, Magnetic anomaly in the vicinity of Japan by high-pass filter method (1981).

T. YUKUTAKE and S. FUJITA, Reduction of observatory data to the period of MAGSAT observation (1981).

M. YANAGISAWA, Crustal magnetization in the vicinity of Japan (1981).

N. FuKUSHIMA, Report on the MAGSAT Investigators' Meeting in Edinburgh in July 1981 (1981).

H. MAedA, T. IYEMORI, T. ARAKI, and T. KAMEI, Evidence of toroidal electric current in the equatorial ionosphere (with regard to $\Delta D$ anomaly) (1981).

T. ARAKI, T. IYEMORI, and H. MAEDA, Magnetic variation at the time of magnetic storms observed by MAGSAT (1981).

Y. Kamide, T. Iijima, N. Fukushima, D. S. Evans, and A. D. Richmond, Simultaneous observation of magnetic field by MAGSAT and precipitating 
particles by TIROS-NOAA satellites (1981).

T. IIJIMA and N. FukUSHIMA, Comparison of field-aligned currents between an extremely quiet day and a severely disturbed day (1981).

A. SuzuKi, T. Kamei, and T. KumaKi, Study of field-aligned current with an application of Maxwell's equation (1981).

N. FukUSHIMA, Comments on the electric current crossing the MAGSAT orbit plane (1981).

Semi-Annual Meetings of the Society of Terrestrial Magnetism and Electricity of Japan

The 68th Meeting, November 1980

H. Sakurai, M. Ejiri, T. IIJima, and N. Fukushima, Reduction of MAGSAT data and comparison with relevant geophysical data (1).

N. Funushima, T. Iijima, R. FujiI, and H. Sakurai, Field-aligned current signatures in MAGSAT data.

M. Kono and M. YANAGISAwA, Preliminary results of MAGSAT data analysis.

H. Maeda, T. Araki, A. Suzuki, and T. KameI, Analysis of geomagnetic variation field with MAGSAT data.

The 69th Meeting, May 1981

M. Kono and M. YANAgisawa, Magnetic anomalies in the vicinity of Japan observed by MAGSAT.

T. IIJIMA, N. FukUShima, R. FUJil, and H. SAKURAI, Characteristics of magnetic field variations observed by MAGSAT satellite.

Y. KAmide, T. IIJIMA, R. FujiI, and N. Fukushima, Simultaneous magnetic observations by MAGSAT and Alaskan chain stations.

A. SuZUKI, T. KameI, and T. KumaKi, Calculation of magnetospheric currents by means of MAGSAT data.

S. Tsunomura, T. Iyemori, H. Maeda, and T. Araki, Analysis of SC with MAGSAT data.

H. MAedA, T. KAMEI, and T. IYemori, Analysis of geomagnetic diurnal variation by means of MAGSAT data.

The 70th Meeting, October 1981

M. Kono and M. YANAGisAwA, Magnetic anomaly in the vicinity of Japan observed by MAGSAT.

A. SuzUKI, T. KAMEI, and T. KUMAKI, Calculation of magnetospheric currents by means of MAGSAT data, II.

T. IIJIMA and N. FuKUSHIMA, Characteraistics of auroral disturbances and polarcap disturbances observed by MAGSAT, and their interpretation.

H. MAedA, T. ARAKI, T. KAMEI, and T. IYemori, Analysis of geomagnetic diurnal variation by means of MAGSAT data, III. 
The 71st Meeting, May 1982

M. YanAgisawa and M. Kono, Corrections on external magnetic fields in the analysis of MAGSAT data.

I. NAKAGAWA and T. YUKUTAKE, Geomagnetic three-component anomalies in the vicinity of Japan obtained through the analysis of MAGSAT data.

A. Suzuki, T. Kamei, and T. Kumaki, Calculation of space current across the MAGSAT orbit (3rd report).

H. MAEDA, T. IYEMORI, T. ARAKI, and T. KAMEI, One-month variation in the intensity of meridional electric current in the ionosphere detected by MAGSAT.

T. IIJima, N. FukUShima, and R. FujiI, Field-aligned currents during magnetic disturbance.

The 72nd Meeting, October 1982

I. NAKAGAWA and T. YUKUTAKE, Geomagnetic three-component anomalies in the vicinity of Japan obtained through the analysis of MAGSAT data.

T. NAKATSUKA and Y. ONO, Mapping of geomagnetic anomalies in the vicinity of Japan by means of MAGSAT data.

M. YANAGISAWA and M. KoNO, Effect of ionospheric currents on geomagnetic anomaly maps by MAGSAT data.

M. YANAGISAWA, Structure of magnetospheric ring-current inferred from an analysis of MAGSAT data.

A. SuzuKi, T. KAMEI, and T. Kumaki, Calculation of magnetospheric current across the MAGSAT orbit (4th report).

H. Maeda, T. Kamei, T. IYemori, and T. ARAKI, Analysis of geomagnetic diurnal variation by means of MAGSAT data, IV.

T. IIJima, N. Fukushima, and R. FujII, Structure of field-aligned currents and associated ionospheric currents.

The 73rd Meeting, April 1983

I. NAKAGAwA and T. YUKUTAKE, Analysis of geomagnetic anomalies in the vicinity of Japan by double Fourier expansion of MAGSAT data.

M. YANAgisAwA and M. Kono, Magnetic anomaly maps obtained from MAGSAT data analysis.

T. ARAKI, T. KAMEI, and T. IYEMORI, Magnetic field distribution in the polar region during the period of northward IMF.

T. KAMEI, T. Araki, H. MAedA, and T. IYemori, Relationship between the $A E$ index and high-latitude currents observed by MAGSAT.

A. SuzUKI and N. FuKuSHIMA, Detection of field-aligned currents by means of MAGSAT data.

M. YANAGISAWA and N. FuKUSHIMA, Dawn-dusk asymmetry of magnetospheric field due to field-aligned currents.

T. IIJIMA, IMF and three-dimensional electric current-system in the 
magnetosphere-ionosphere.

The 74th Meeting, October 1983

T. Araki, T. KAMEI, and T. IYemori, Magnetic field distribution in the polar region during the period of northward IMF, II.

T. IIJIMA and APL Group, Persistent Birkeland currents associated with northward IMF.

K. OTA and T. IIJIMA, Dynamic structure of field-aligned currents during polar magnetic disturbances.

The 75th Meeting, May 1984

M. YANAGISAwA and M. Kono, Magnetic anomaly maps obtained from MAGSAT data analysis, II.

M. YANAGISAWA and N. FuKUSHIMA, Dawn-dusk asymmetry of magnetospheric field due to field-aligned currents, II.

T. ARAKI and Y. YAMADA, Interpretation for SC observed simultaneously above and below the ionosphere.

T. KAMEI, Characteristics of polar-cap current-system controlled by IMF $\boldsymbol{B}_{\boldsymbol{y}}$.

N. Fukushima, A. Suzuki, and M. YanAgisawa, Relationship between partial ring current and the space current below the MAGSAT level.

T. IIJIMA and APL/JHU Group, Dependence on IMF $\boldsymbol{B}_{\boldsymbol{y}}$ of Birkeland currentsystem associated with northward IMF.

K. OTA and T. Injma, Progressive change in Birkeland current-system during the stage of Dst development. 